\title{
ERRATUM
}

Chenna Reddy Aswath · Sug Youn Mo •

Doo Hwan Kim • Se Won Park

\section{Agrobacterium and biolistic transformation of onion using non-antibiotic selection marker phosphomannose isomerase}

Published online: 14 April 2006

(C) Springer-Verlag 2005

\section{Plant Cell Reports DOI 10.1007/s00299-005-0022-4}

Unfortunately, the name of the corresponding author and his e-mail address were published incorrectly. The correct name and e-mail address are given below:

Se Won Park

e-mail: sewpark@konkuk.ac.kr

Moreover, the DOI of the article is incorrect in the online pdf version and in the print version.

The correct DOI is 10.1007/s00299-005-0022-4.

The online version of the original article can be found at http://dx.doi.org/ 10.1007/s00299-005-0022-4

C. R. Aswath

Indian Institute of Horticultural Research, Bangalore, 560089, India

e-mail: aswath@iihr.ernet.in

S. Y. Mo · D. H. Kim · S. W. Park $(\bowtie)$

Department of Horticultural Science, Konkuk University,

Seoul, South Korea

e-mail: sewpark@konkuk.ac.kr

email:mosy0708@hanmail.net

email:Kimdh@konkuk.ac.kr 